\title{
Is Cardiac Shock Wave Therapy an Option for the Treatment of Myocardial Ischemia in Patients with Refractory Angina?
}

\author{
Francesco Nudi, MD, ${ }^{\mathrm{a}, \mathrm{b}}$ and Fabrizio Tomai, MD, FACC, FESC ${ }^{\mathrm{b}, \mathrm{c}}$ \\ a Service of Hybrid Cardio Imaging, Madonna Della Fiducia Clinic, Rome, Italy \\ b Replycare, Rome, Italy \\ c Department of Cardiovascular Sciences, European Hospital, Rome, Italy
}

Received Sep 21, 2021; accepted Sep 21, 2021

doi: $10.1007 / \mathrm{s} 12350-021-02821-5$

\section{See related article, pp. 2404-2419}

Optimal medical therapy and percutaneous or surgical coronary revascularization are well-established tools for the treatment of patients with chronic coronary syndromes. However, as the population ages and mortality from coronary artery disease (CAD) decrease, a growing number of patients with severe CAD continue to experience angina which is not amenable to surgical or percutaneous coronary revascularization despite excellent medical therapy. Overall, the prevalence of this condition, defined as refractory angina, ${ }^{1}$ is estimated to be $5 \%$ to $10 \%$ in stable CAD patients, possibly accounting for 50,000 to 100,000 new cases/year in the USA and 30,000 to 50,000 new cases/year in Europe. ${ }^{2}$ The general definition of refractory angina includes patients with anatomic reasons precluding revascularization (severe diffuse disease, lack of graft conduits for surgical revascularization, multiple coronary restenoses, degenerated saphenous vein grafts), patients with severe comorbidities (advanced age, pulmonary obstructive chronic disease, high-risk procedure), or patients with coronary disorders other than obstructive CAD causing angina (microvascular dysfunction). ${ }^{3,4}$ Currently, treatment option for this setting of patients is limited to implementation of traditional anti-anginal therapy with the inclusion of novel pharmacological agents (i.e.,

Reprint requests: Francesco Nudi, MD, Service of Hybrid Cardio Imaging, Madonna Della Fiducia Clinic, Rome, Italy; francesco.nudi@replycare.com

J Nucl Cardiol 2022;29:2420-2.

$1071-3581 / \$ 34.00$

Copyright (C) 2021 American Society of Nuclear Cardiology. ranolazine) and secondary risk-factors modification. Thus, a variety of alternative treatment modalities of refractory angina are being investigated. These include transmyocardial laser revascularization, ${ }^{5}$ enhanced external counterpulsation, ${ }^{6}$ spinal cord stimulation, ${ }^{7}$ transcutaneous electrical nerve stimulation, ${ }^{8}$ stem cell therapy ${ }^{9}$, and coronary sinus reducer. ${ }^{10}$ Some studies showed that all these nonpharmacological treatments may reduce anginal symptoms and improve exercise capacity, myocardial perfusion, and function in patients with refractory angina. However, these benefits were not consistent across all studies and, currently, only transmyocardial laser revascularization, enhanced external counterpulsation, and spinal cord stimulation have a IIb/ $\mathrm{B}$ class of recommendation in the ACC/AHA guidelines. Some characteristics of these alternative therapeutic technologies are shown in the Table 1.

Ultrasound-guided cardiac shock wave therapy (CSWT) is another promising non-invasive treatment modality in patients with stable CAD. ${ }^{4}$ It has been developed based on the lithotripsy method; it uses application of low-intensity shock waves to stimulate angiogenesis. ${ }^{11}$ Specifically, several experimental studies have demonstrated that the application of lowintensity shock waves might induce the release of angiogenic factors such as endothelial nitric oxide synthase, vascular endothelial growth factor, and proliferating cell antinuclear antigen. ${ }^{11} \mathrm{CSWT}$ is delivered using a generator accompanied by a cardiac ultrasound system to target the myocardial ischemic area of interest. Improvements in symptoms, cardiac function, and ischemic threshold have been reported with CSWT in small placebo-controlled trials and real-world registries. ${ }^{4}$ Notably, a recent meta-analysis of 39 studies with 1,006 patients treated with CSWT showed moderate improvement in exercise capacity, thus suggesting that CSWT is a potentially effective non-invasive option 
Table 1. Alternative therapeutic technologies in refractory angina

\begin{tabular}{|c|c|c|c|}
\hline Treatment & Mechanism of action & Efficacy & $\begin{array}{l}\text { Potential } \\
\text { complications }\end{array}$ \\
\hline $\begin{array}{l}\text { Transmyocardial laser } \\
\text { revascularization }\end{array}$ & $\begin{array}{l}\text { Laser-created intramyocardial transmural } \\
\text { channels; angiogenesis; denervation }\end{array}$ & ++ & Major \\
\hline $\begin{array}{l}\text { Enhanced external } \\
\text { counterpulsation }\end{array}$ & $\begin{array}{l}\text { Improved diastolic coronary perfusion; reduced } \\
\text { afterload }\end{array}$ & +++ & Minor \\
\hline Spinal cord stimulation & Pain signal neuromodulation & +++ & Major \\
\hline $\begin{array}{l}\text { Transcutaneous electrical } \\
\text { nerve stimulation }\end{array}$ & Pain signal neuromodulation & + & No \\
\hline Stem cell therapy & Neovascularization; endothelial protection & +++ & Minor \\
\hline Coronary sinus reducer & Coronary flow redistribution & +++ & Minor \\
\hline Cardiac shock wave therapy & Neoangiogenesis; improved myocardial perfusion & ++ & No \\
\hline
\end{tabular}
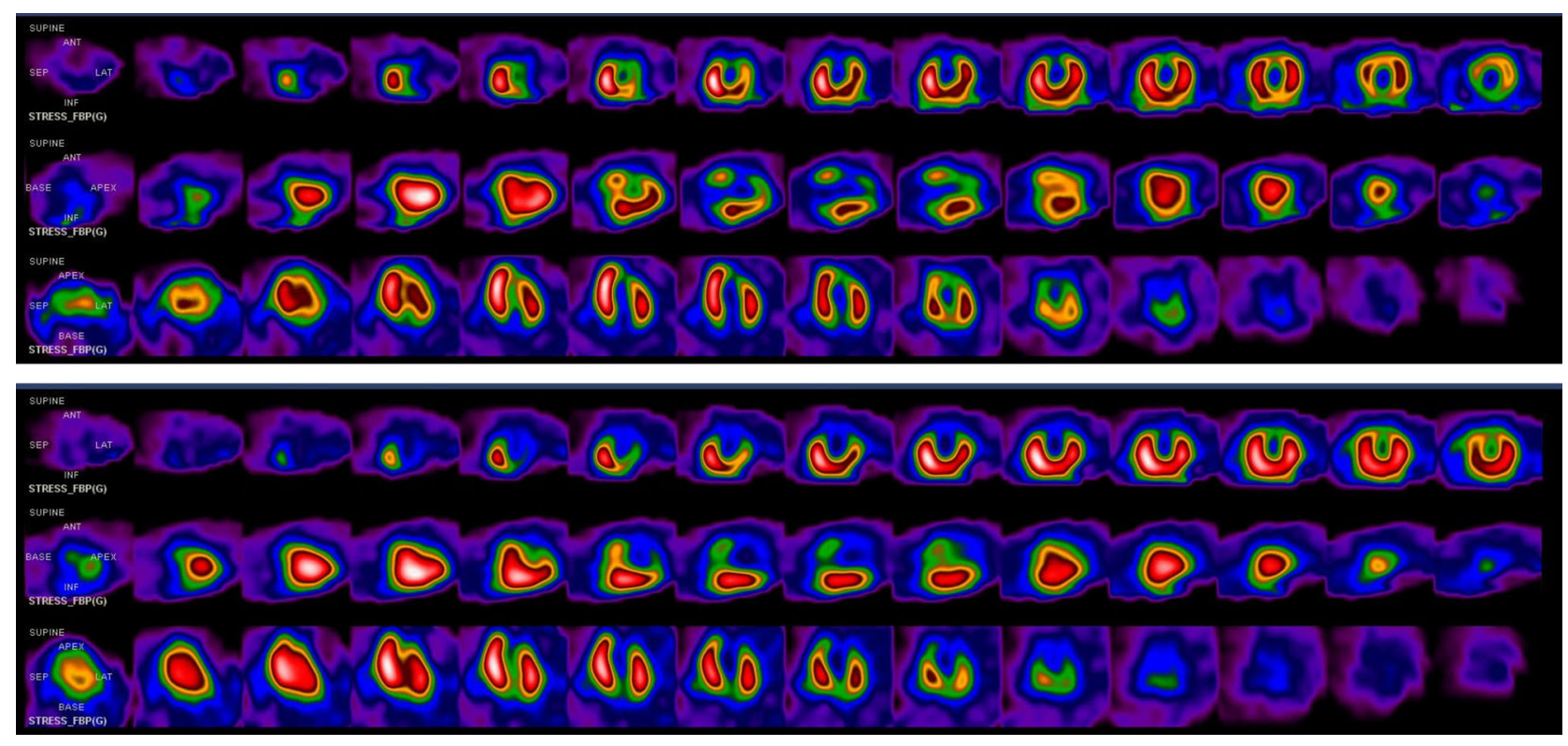

Figure 1. Myocardial perfusion imaging with dipyridamole (up) and with bicycle exercise test (down), in the same patient with LAD coronary artery stenosis. A perfusion defect is present in the anterior wall and apex with dipyridamole stress; the size and severity of the defect is greater after exercise stress.

for patients with $\mathrm{CAD}$, but evidence is limited to small low/moderate quality single-center studies. ${ }^{12}$

In this issue of the Journal of Nuclear Cardiology, Jia et $\mathrm{al}^{13}$ report the results of another randomized, double-blind control study, aimed at assessing efficacy and safety of CSWT in patients with severe CAD unsuitable for coronary revascularization, with more than two ischemic segments at myocardial perfusion imaging, refractory angina, and left ventricular (LV) ejection fraction $\geq 30 \%$. Stress perfusion imaging was used to identify the two LV segments with the most severe reversible perfusion defect, which were the segments targeted during treatment.

They found a statistically significant improvement of global and regional (segments targeted) myocardial perfusion in CSWT-treated patients, without significant difference in clinical symptom, quality of life, and exercise tolerance between groups. No procedural complications or adverse effects were noted, confirming the safety of CSWT.

The evaluation of myocardial perfusion as primary endpoint (i.e., total perfusion score) seems to be 
adequate, being angiogenesis with improved coronary perfusion the proposed anti-ischemic (antianginal) pathophysiological target of CSWT. It should be noted, however, that the possibility of quantitative measurements, using positron emission tomography or cadmium zinc telluride technology, would allow a more precise estimate of the quantification of global perfusion, that could be partially underestimated with the SPECT, especially in the presence of balanced ischemia, frequently found in these patients. In this regard, the most accurate estimation of the extension and severity of the ischemic area to be targeted during treatment would optimize the efficacy of CSWT in terms of ischemia reduction and relief of angina. Furthermore, although the authors utilized a dynamic or a pharmacological stress test depending on the patient's condition, it would have been more appropriate in these patients the use of a dynamic exercise test, as the alteration of perfusion associated with anginal symptoms accurately represents the ischemic area to be treated. Of note, with pharmacological testing, the extent and severity of a perfusion defect may be underestimated, making less accurate the evaluation of the possible reduction of ischemia after treatment $^{14}$ (Figure 1). Finally, the authors enrolled patients with normal LV geometry and function, despite more than $50 \%$ were revascularized, and around 30\% had previous myocardial infarction or a NYHA class 3 . It would be interesting to evaluate the efficacy of CSWT also in patients with LV dysfunction, in whom the reduction of ischemic burden may have a prognostic benefit.

In conclusion, CSWT seems to improve myocardial perfusion in patients with severe CAD, but it remains unanswered its efficacy in the reduction of anginal symptoms, which should be the most important goal in this specific clinical setting. Similarly to previous studies, it is likely that the small sample size, the improvements in the placebo group, and the limited period of follow-up of this trial preclude definitive conclusions on the efficacy of CSWT. Thus, 20 years after its introduction, CSWT cannot yet be considered a further therapeutic option in patients with refractory angina. Larger multicenter, adequately powered, randomized double-blind studies are required to define the role of CSWT in this setting of patients, to decrease nonresponder rates and ascertain benefit beyond potential placebo effects.

\section{Disclosure}

All authors disclose no potential conflict of interest.

\section{References}

1. Mannheimer C, Camici P, Chester MR, Collins A, DeJongste M, Eliasson T. The problem of chronic refractory angina: Report from the European Society of Cardiology joint study group on the treatment of refractory angina. Eur Heart J 2002;23:355-70.

2. Henry TD, Satran D, Jolicoeur EM. Treatment of refractory angina in patients not suitable for revascularization. Nat Rev Cardiol 2014;11:78-95.

3. Jolicoeur EM, Cartier R, Henry TD, Barsness GW, Bourassa MG, McGillion M, et al. Patients with coronary artery disease unsuitable for revascularization: Definition, general principles, and a classification. Can J Cardiol 2012;28:S50-9.

4. Gallone G, Baldetti L, Tzanis G, Gramegna M, Latib A, Colombo A, et al. Refractory angina: From pathophysiology to new therapeutic nonpharmacological technologies. J Am Coll Cardiol Intv 2020;13:1-19.

5. Oesterele SN, Sanborn TA, Ali N, Resar J, Ramee SR, Heuser R, et al. Percutaneous transmyocardial laser revascularization for severe angina: The PACIFIC randomized trial. Potential class improvement from intramyocardial channels. Lancet 2000;356:1705-10.

6. Arora RR, Chou TM, Jain D, Fleishman B, Crawford L, McKiernan T, et al. The multicenter study of enhanced external counterpulsation (MUST-EECP): Effect of EECP on exercise-induced myocardial ischemia and anginal episodes. J Am Coll Cardiol 1999;33:1833-40.

7. Taylor RS, De Vries J, Bucher E, Dejongste MJ. Spinal cord stimulation in the treatment of refrctory angina: Systematic review and metaanalysis of randomised controlled trials. BMC Cardiovasc Disord 2009;9:13.

8. Borjesson M, Eriksson P, Dellborg M, Eliasson T, Mannheimer C. Transcutaneous electrical nerve stimulation in unstable angina pectoris. Coron Artery Dis 1997;8:543-50.

9. Henry TD, Schaer GL, Traverse JH, Povsic TJ, Davidson C, Lee JS, et al. Autologous CD34(p) cell therapy for refractory angina: 2-year outcomes from the ACT34-CMI study. Cell Transplant 2016;25:1701-11

10. Verheye S, Jolicoeur EM, Behan MW, Pettersson T, Sainsbury P, Hill J, et al. Efficacy of a device to narrow the coronary sinus in refractory angina. N Engl J Med 2015;372:519-27.

11. Alunni G, Marra S, Meynet I, D'amico M, Pelloni E, Fanelli A, et al. The beneficial effect of extracorporeal shockwave myocardial revascularization in patients with refractory angina. Cardiovasc Revasc Med 2015;16:6-11.

12. Burneikaite G, Shkolnik E, Celutkiene J, Zuozienė G, Butkuviené I, Petrauskiene B, et al. Cardiac shock-wave therapy in the treatment of coronary artery disease: Systematic review and metaanalysis. Cardiovasc Ultrasound 2017;15:11.

13. Jia N, Zhang R, Liu B, Liu B, Qi X, Lan M, et al. Efficacy and safety of cardiac shock wave therapy for patients with severe coronary artery disease: A randomized, double-blind control study. J Nucl Cardiol 2021. https://doi.org/10.1007/s12350-021-02768-7.

14. Chow BJW, Beanlands RS, Lee A, DaSilva JN, deKemp RA, Alkahtani A, et al. Treadmill exercise produces larger perfusion defects than dipyridamole stress N-13 ammonia Positron emission tomography. J Am Coll Cardiol 2006;47:411-6.

Publisher's Note Springer Nature remains neutral with regard to jurisdictional claims in published maps and institutional affiliations. 